\title{
Review \\ Pro/Con debate: Is procalcitonin useful for guiding antibiotic decision making in critically ill patients?
}

Yahya Shehabi ${ }^{1}$ and lan Seppelt ${ }^{2}$

\author{
${ }^{1}$ Acute Care Clinical Program, Intensive Care and Research, Prince of Wales Hospital, University of New South Wales, Barker Street, Randwick, \\ NSW 2031, Australia \\ ${ }^{2}$ Department of Intensive Care Medicine, Nepean Hospital, University of Sydney, Derby Street, Penrith, NSW 2751, Australia
}

Corresponding author: Yahya Shehabi, y.shehabi@unsw.edu.au

Published: 2 May 2008

This article is online at http://ccforum.com/content/12/3/211

(c) 2008 BioMed Central Ltd

Critical Care 2008, 12:211 (doi:10.1186/cc6860)

More specifically, a useful sepsis biomarker should do the following [4]: (a) add value to the clinical evaluation, (b) shorten the time to definitive diagnosis, and (c) differentiate infectious and bacterial from noninfectious or nonbacterial causes. The utility of a biomarker is enhanced if it reflects (i) the severity of infection and the septic process and (ii) the effectiveness of therapy, including antibiotics, earlier and more accurately than clinical convention.

\section{Pro: Time for goal-directed procalcitonin- guided antibiotic therapy in the intensive care unit}

More than 40\% of the patients in European and Australasian intensive care units (ICUs) have sepsis or severe sepsis, but only $58 \%$ of clinically suspected infections are confirmed by positive culture [1]. While it is perfectly justifiable to commence broad-spectrum antibiotics early, the decision to continue or cease such therapy remains an arbitrary one by the treating intensivist. This can lead to the indiscriminate overuse of antimicrobials, with significant cost implications and (of far greater concern) increasingly frequent outbreaks of resistant organisms [2].

\section{Procalcitonin is a SMART biomarker for sepsis and infection}

While fever, leukocytosis, and other responses to systemic inflammation are clinical signs consistent with sepsis and infection [3], they are neither specific nor sensitive to guide antibiotic therapy at any stage during sepsis management. A useful biomarker for sepsis must be Specific (as well as Sensitive), Measurable with a high degree of precision, readily Available (and Affordable), Responsive and Reproducible, with results available in a Timely fashion to guide therapy (SMART).

\begin{abstract}
You are concerned about the escalating use of antibiotics in your intensive care unit (ICU). This has put a strain on the ICU budget You review the situation with your team and one suggestion is to consider using biomarkers such as procalcitonin to better guide appropriate antibiotic decision making.
\end{abstract}

Procalcitonin (PCT) normally has a plasma level of less than $0.1 \mu \mathrm{g} / \mathrm{L}(\mathrm{ng} / \mathrm{mL})$ in healthy subjects. Levels rise substantially in response to triggers released during bacterial and systemic infections, in particular endotoxin and inflammatory cytokines. The elimination half-life of PCT is between 22 and 35 hours. Whereas endotoxin and most other inflammatory cytokines (tumor necrosis factor-alpha and interleukin [IL]-1) are undetectable within 24 hours of an endotoxin challenge, PCT starts to rise at 4 hours and peaks at between 8 and 24 hours and C-reactive protein (CRP) rises slowly and peaks 36 hours after an endotoxin challenge [5].

PCT fulfills most of the criteria for a SMART biomarker. The specificity and negative predictive value of PCT have been substantially enhanced in newer assays by the improved functional assay sensitivity of an amplified cryptate emission technique $[6,7]$. The biostability of PCT makes it measurable within a realistic clinical window with an assay that is available and relatively affordable. PCT is responsive and reflects the severity of the disease process and effectiveness of therapeutic interventions [8]. With a half-life of about 24 hours, it allows for timely repeated measurements that may reflect changes of the underlying clinical condition due to therapy.

$\mathrm{COPD}=$ chronic obstructive pulmonary disease; $\mathrm{CRP}=\mathrm{C}$-reactive protein; ICU = intensive care unit; IL = interleukin; PCT = procalcitonin; RCT = randomised controlled trial; ROC AUC = area under the receiver operating curve; SMART = Specific (and Sensitive), Measurable, Available (and Affordable), Responsive and Reproducible, and Timely. 
PCT-guided management of antibiotics in the ICU requires clinicians to change from their usual affirmative diagnostic mindset to one in which negative confirmation is more important (that is, that infection is extremely unlikely and therefore antibiotics are inappropriate). The negative predictive value of PCT for bacterial and systemic infection is almost $99 \%$. This should be the cornerstone of such a strategy.

The clinical utility of a PCT assay was reported as early as 1993, when Assicot and colleagues [9] described high PCT blood levels in patients with severe bacterial infections and low levels in those without infection ( 6 to 53 versus less than $0.1 \mu \mathrm{g} / \mathrm{L}$, respectively). They described a rapid decline in PCT levels with antibiotic therapy and slightly elevated levels $(0.1$ to $1.5 \mu \mathrm{g} / \mathrm{L})$ in patients with noninvasive infections. It was suggested more recently that a cutoff level of $0.5 \mu \mathrm{g} / \mathrm{L}$ had a specificity of $96 \%$ in differentiating between bacterial infections and other inflammatory processes [10]. At this cutoff of $0.5 \mu \mathrm{g} / \mathrm{L}$, the area under the receiver operating curve (ROC AUC) discriminating bacterial from nonbacterial infections was the highest at 0.84 for PCT when compared with endotoxin, IL-6, and CRP $(0.60,0.77$, and 0.78, respectively) [11].

Recent trials have supported these earlier results, with strong evidence in specific clinical areas, particularly respiratory infections. Using a PCT-guided strategy, the ProRESP (procalcitonin in lower respiratory tract infection) study in Basel, Switzerland, reported a 50\% reduction in antibiotic usage in patients with lower respiratory tract infection [12]. A similar study in suspected community-acquired pneumonia (procalcitonin in patients with community-acquired pneumonia [ProCAP]), which used a PCT threshold of $0.25 \mu \mathrm{g} / \mathrm{L}$ with a serial assay in 302 patients, led to a significant reduction of both the duration of therapy and the overall prescription of antibiotics in the PCT-guided arm compared with conventional treatment guidelines (5.8 versus 12.9 days and $85 \%$ versus 99\%, respectively) [13]. Antibiotic discontinuation rates were significantly higher in the PCTguided group. Stolz and colleagues [14] reported similar results in a randomised trial (procalcitonin in chronic obstructive lung disease [ProCOLD]) that included 208 patients with exacerbation of chronic obstructive pulmonary disease (COPD) using a cutoff value of $0.1 \mu \mathrm{g} / \mathrm{L}$ measured on hospital admission, with a $31.5 \%$ absolute reduction in antibiotic exposure.

PCT has been shown to be the only independent variable associated with the diagnosis of systemic infection, with up to $99 \%$ specificity using a cutoff value of $0.5 \mu \mathrm{g} / \mathrm{L}$ [15]. These findings could not be replicated with a single PCT assay in 243 febrile patients with a cutoff value of $0.2 \mu \mathrm{g} / \mathrm{L}$ [16]. This emphasises the importance of serial PCT measurements and integration of clinical findings into decision-making processes.
Patients with severe pancreatitis who developed infective necrosis or multiorgan dysfunction showed a sustained increase in PCT levels. Unlike CRP, a striking discrimination early in the course was observed with PCT. A relatively high threshold of $3.5 \mu \mathrm{g} / \mathrm{L}$ gave a negative predictive value for infective necrosis of $99 \%$ [17]. When the maximum recorded PCT was used, the ROC AUC values were 0.86, 0.91, and 0.89 for infective necrosis associated with multiorgan dysfunction, nonsurvival, or the combination of the two, respectively [17].

In the postoperative cardiac surgery patients, a PCT value of greater than $1.5 \mu \mathrm{g} / \mathrm{L}$ after the second postoperative day was a much better predictor of infection than IL-6, IL-8, CRP, or leukocytosis and was significantly higher in patients who died [18].

The availability of a SMART biomarker like PCT, used as a surrogate for bacterial infection, offers intensivists a golden opportunity to rethink our approach to therapy in patients with suspected infections in the ICU, and in particular the blind and often inappropriate use of antibiotics. We must move beyond the question of whether we should or should not use PCT for antibiotic guidance and address the more critical questions of integrating PCT into effective clinical decision making and assess the full potential of its use in large-scale clinical trials [19].

Müller and colleagues [19] have recommended a PCTguided diagnostic algorithm for patients with suspected sepsis. This is based on data available to date which indicate that a PCT of less than $0.1 \mu \mathrm{g} / \mathrm{L}$ rules out bacterial infection, so antibiotics should not be used. Similarly, antibiotic use is discouraged if the PCT is less than $0.25 \mu \mathrm{g} / \mathrm{L}$. A rising PCT should prompt a review of antibiotics or source control in patients with systemic infections [19]. The algorithm (Figure 1) is practical and simple.

The criterion 'admission to ICU' in Figure 1 refers to patients who are not in the ICU. If those patients require admission to the ICU, then reassessment and repeat PCT 6 to 24 hours after admission may be indicated. For patients who are already in the ICU, this criterion clearly does not apply. Recently, a similar strategy was evaluated on a small number of septic intensive care patients, with a significant reduction in antibiotic usage [20].

While quality of care must be the primary objective driving practice change, cost saving is a positive side effect. This simple strategy can result in a reduction of up to $30 \%$ in the cost of antibiotics. In an Australian general ICU (22 beds), this is equivalent to about US $\$ 80,000$ per annum. The impact of reduction in antibiotic usage on the emergence of resistant organisms is a strategic gain that needs to be addressed in adequately powered longitudinal clinical trials. 


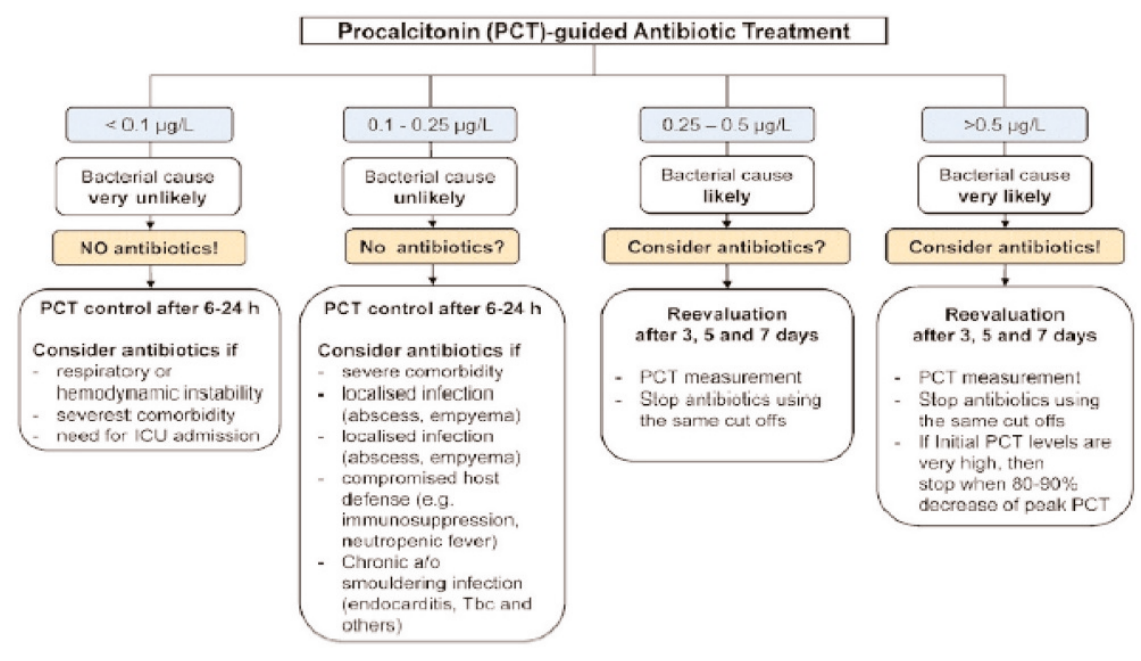

Proposed algorithm for procalcitonin (PCT)-guided antibiotic therapy. ICU, intensive care unit. Reprinted with permission from Müller and colleagues [19].

\section{Con: PCT has not yet been validated for this purpose in critical illness, so wait for the trials}

It is increasingly clear that there is no 'gold standard' biomarker for sepsis. Four systematic reviews with metaanalysis of PCT studies have been published in the last few years [21-24]. While each looked at different patient groups and included slightly different studies and some of the methodology has been questioned, it is clear from each of these analyses that, at best, PCT has only moderate positive predictive value and is best used as one part of a comprehensive clinical evaluation of the patient.

This scenario looks at the opposite use of the PCT assay, for its negative predictive value, asserting that a patient with a low PCT does NOT have bacterial sepsis. Although a recent trial supports this notion in septic patients, numbers were small with many exclusions [20]. However, there are good data to support this assertion in other specific patient groups, particularly patients with lower respiratory tract infections, community-acquired pneumonia, or patients with exacerbations of COPD presenting to the emergency department, where a PCT-guided treatment algorithm can significantly reduce antibiotic use and duration of therapy without any adverse effect on patient outcomes [12-14]. An observational study during an outbreak of viral meningitis in children used PCT to reduce unnecessary antibiotic use [25]. So while the emergency department experience is positive, particularly for respiratory infections, we are still waiting for a large trial that evaluates PCT for this purpose in the critically ill, and until such trials have been completed, we must be cautious.

Indeed, a number of randomised controlled trials (RCTs) are currently under way in intensive care patients, and if we accept that there is clinical equipoise for these studies, it is crucial that we await their results! The Danish Procalcitonin Study Group is conducting an RCT of a PCT-guided strategy with mortality endpoints in critically ill patients (NCT00271752) [26]. A French study is looking at another large group of septic ICU patients (NCT00472667) [26]. A third study in the US and Germany will be looking at the discontinuation of antibiotics in ICU patients using a PCT-guided strategy (NCT00407147) [26]. A fourth RCT in Switzerland is looking specifically at PCT-guided strategies in ventilator-associated pneumonia (ISRCTN61015974) [27].

In 2008, we can speculate that a PCT-guided antibiotic strategy in the ICU might be efficacious but such a strategy must be properly tested in a heterogenous group of critically ill patients. So until these clinical trials have been completed, we must keep an open mind about the generalisability of findings from studies of specific disease processes. As well as efficacy, we must consider safety. A strategy that recommends withholding antibiotics but ends up harming patients (by not giving the necessary antibiotics) is also of concern.

The PCT threshold for 'suspected' sepsis in critically ill patients has not been adequately defined and varies significantly from study to study. Different trials have used cutoff values of $0.1,0.25,0.4$, or $0.5 \mu \mathrm{g} / \mathrm{L}$. It is becoming clear that patients with a PCT between 0.25 and $0.5 \mu \mathrm{g} / \mathrm{L}$ may still have sepsis (so a threshold of $0.5 \mu \mathrm{g} / \mathrm{L}$ is inappropriate), but sufficient research has not yet been done to define precisely where the threshold should be $(0.25$ or $0.1 \mu \mathrm{g} / \mathrm{L}$ or some other number). Very different thresholds have been reported in necrotising pancreatitis and after cardiac surgery $[17,18]$, which makes interpretation of this literature quite difficult and 
confusing. In a meta-analysis of diagnostic studies in critically ill patients, a specific threshold effect could not be identified [24], making the point that PCT is better used as a tool to stratify risk in the clinical context than specifically as a binary indicator. A large epidemiological study is required in intensive care to specifically address the question of the most appropriate PCT threshold(s) before the negative prediction strategy in the scenario can be considered validated.

The threshold also depends on the type of assay used. Earlier studies used a quantitative assay with a limited functional assay sensitivity of 0.3 to $0.5 \mu \mathrm{g} / \mathrm{L}$, whereas more recently an assay with a functional sensitivity of $0.06 \mu \mathrm{g} / \mathrm{L}$ has been available [28]. Clinical trials using a PCT-guided decision tool must be interpreted in light of the functional sensitivity of the assay used. All recent research has used the TRACE (timeresolved amplified cryptate emission) technology assay (Kryptor PCT; B.R.A.H.M.S Aktiengesellschaft, Henningsdorf, Germany). It is crucial to know what assay is available to your hospital before making any conclusions about the appropriateness of a 'low PCT' strategy to guide antibiotic therapy.

In addition to the quantitative assays, a semiquantitative point-of-care test kit is available, and for reasons of cost and speed, this is becoming popular (PCT-Q, a one-step immunochromographic assay; B.R.A.H.M.S Aktiengesellschaft). After 30 minutes, this kit gives one of four responses: $\mathrm{PCT}<0.5$, 0.5 to $<2,2$ to 10 , or $>10 \mu \mathrm{g} / \mathrm{L}$. The ' $<0.5 \mu \mathrm{g} / \mathrm{L}$ ' response of this kit is used by clinicians to indicate that 'bacterial sepsis is unlikely', but the threshold is probably too high for this conclusion to be valid.

Finally, the time course and kinetics of PCT must be considered. Falsely low levels will be seen if the PCT is measured too early in the time course of an illness. Falsely high levels may be seen after surgery, trauma, and burns but will fall rapidly on serial testing [19].

It is clear that PCT is not a 'magic marker' for the positive diagnosis of sepsis, nor has it yet been sufficiently validated for the negative exclusion of sepsis in intensive care, although it may well fit this role. As a matter of pragmatism, no biomarker should ever be used in isolation for decision making. It is one tool in the clinician's armamentarium and must be considered in conjunction with clinical examination, other laboratory tests, and microbiological results. Algorithms taking all of these factors into account are now being evaluated [19]. In addition, newer laboratory techniques such as multiplex polymerase chain reaction and microarray gene mapping may become an essential part of the assessment of sepsis in the future [29].

For PCT to be a useful assay to exclude infection and reduce antibiotic use, results must be readily available to the clinician for decision making, it must be sensitive and well validated at low concentrations, and it must be cost-effective, taking into account the equipment cost and day-to-day costs in the laboratory. PCT has not yet been shown to fulfill this role in critical illness.

\section{Conclusion}

While intensive care research that is more specific is needed to validate this approach and a number of important trials are currently under way, the scientific foundation for a PCTguided strategy to antibiotic therapy in intensive care is in place. PCT has been tested in a number of the clinical conditions (respiratory, abdominal, and postoperative infections) that constitute the majority of infections treated in intensive care. However, clinicians must be absolutely confident that ALL patients who have an infection are appropriately treated when using a PCT-guided negative prediction strategy.

In many ways, PCT can be considered analogous to betteraccepted biomarkers such as troponin $\mathrm{T}$, which has a clear threshold $(0.1 \mu \mathrm{g} / \mathrm{mL})$ and an excellent negative predictive value for myocardial ischaemia, even though it can be elevated in a number of other conditions such as sepsis and renal failure, so elevated levels must be interpreted in the context of the individual patient $[30,31]$.

A number of prerequisites must be fulfilled before a PCTguided strategy can become ubiquitous in intensive care:

1. Intensivists must understand the limitations of PCT. It is not a gold standard for the diagnosis of sepsis. It has no value in the assessment of fungal or viral infections and shows no response to intracellular microorganisms (such as Mycoplasma) or in local infections with no systemic response. Similarly, there are clinical conditions with a high-baseline PCT like burns, major surgery, and systemic inflammatory processes, which is why PCT is much more useful for its negative predictive value.

2. The best PCT threshold still needs to be clearly defined in critical illness, and it may be that there will be different cutoff values recommended for negative prediction in different clinical infections (for example, postcardiac surgery, infective endocarditis, chest infections, and paediatric infections). This makes the universal use of a single negative predictive cutoff value more difficult, although in general terms, the chance of significant sepsis with a PCT of less than $0.1 \mu \mathrm{g} / \mathrm{L}$ is negligible, and therefore a single negative predictive cutoff value can be used in a simple predictive algorithm (Figure 1) [19].

3. The PCT assay must be a quantitative one with an appropriate functional sensitivity to detect low levels of PCT. The use of semiquantitative test kits is likely to be problematic, with their high threshold $(0.5 \mu \mathrm{g} / \mathrm{L})$ increasing the risk of false negatives. This may potentially mislead clinicians.

4. Serial (daily) PCT levels should be used to monitor progress over time. PCT can be used to assess the adequacy of therapeutic interventions. If the level fails to approximately halve each day or (especially) if levels start 
to rise, the adequacy of treatment must be questioned, leading perhaps to a change of antibiotics or surgical intervention.

It is now time to validate a PCT-guided algorithm in largescale trials in critically ill patients, and the results of several such trials are awaited. In the meantime, we support a simple algorithm with cutoff values of less than $0.1 \mu \mathrm{g} / \mathrm{L}$ (no antibiotics indicated) and less than $0.25 \mu \mathrm{g} / \mathrm{L}$ (discourage antibiotics). This is appropriate and can be very useful for the scenario given and is likely to produce a significant reduction in antibiotic usage and a substantial reduction in costs, without any evidence that patients will be put at risk.

\section{Competing interests}

The authors declare that they have no competing interests.

\section{References}

1. French C: The epidemiology of sepsis - is Australasia different? Crit Care Resusc 2006, 8:219-222.

2. Thursky KA, Buising KL, Bak N, MacGregor L, Street AC, Macintyre CR, Presneill JJ, Cade JF, Brown GV: Reduction of broadspectrum antibiotic use with computerized decision support in an intensive care unit. Int J Qual Health Care 2006, 18:224231.

3. Abraham E, Matthay MA, Dinarello CA, Vincent JL, Cohen J, Opal SM, Glauser M, Parsons P, Fisher CJ Jr., Repine JE: Consensus conference definitions for sepsis, septic shock, acute lung injury, and acute respiratory distress syndrome: time for a reevaluation. Crit Care Med 2000, 28:232-235.

4. Reinhart K, Meisner M, Brunkhorst F: Markers for sepsis diagnosis: what is useful? Crit Care Clin 2006, 22:503-519.

5. Reinhart K, Karzai W, Meisner M: Procalcitonin as a marker of the systemic inflammatory response to infection. Intens Care Med 2000, 26:1193-1200.

6. Steinbach G, Rau B, Debard AL, Javourez JF, Bienvenu J, Ponzio A, Bonfa A, Hubl W, Demant T, Kulpmann WR, Buchholz J, Schumann G: Multicenter evaluation of a new immunoassay for procalcitonin measurement on the Kryptor System. Clin Chem Lab Med 2004, 42:440-449.

7. Morgenthaler NG, Struck J, Fischer-Schulz C, Seidel-Mueller E, Beier W, Bergmann A: Detection of procalcitonin (PCT) in healthy controls and patients with local infection by a sensitive ILMA. Clin Lab 2002, 48:263-270.

8. Jensen J, Heslet L, Jensen T, Espersen K, Steffensen P, Tvede M: Procalcitonin increase in early identification of critically ill patients at high risk of mortality. Crit Care Med 2006, 34: 2596-2602.

9 Assicot M, Gendrel D, Carsin H, Raymond J, Guilbaud J, Bohuon $\mathrm{C}$ : High serum procalcitonin concentrations in patients with sepsis and infection. Lancet 1993, 341:515-518.

10. Delévaux I, Andre M, Colombier M, Albuisson E, Meylheuc F, Bégue R-J, Piette J-C, Aumaître O: Can procalcitonin measurement help in differentiating between bacterial infection and other kinds of inflammatory processes? Ann Rheum Dis 2003, 62:337-340.

11. Aikawa N, Fujishima S, Endo S, Sekine I, Kogawa K, Yamamoto Y, Kushimoto S, Yukioka H, Kato N, Totsuka K, Kikuchi K, Ikeda T, Ikeda K, Harada K, Satomura S: Multicenter prospective study of procalcitonin as an indicator of sepsis. J Infect Chemother 2005, 11:152-159.

12. Christ-Crain M, Jaccard-Stolz $D$, Bingisser $R$, Gencay MM, Huber PR, Tamm M, Müller B: Effect of procalcitonin-guided treatment on antibiotic use and outcome in lower respiratory tract infections: cluster-randomised, single-blinded intervention trial. Lancet 2004, 363:600-607.

13. Christ-Crain M, Stolz D, Bingisser R, Müller C, Miedinger D, Huber PR, Zimmerli W, Harbarth S, Tamm M, Müller B: Procalcitonin guidance of antibiotic therapy in community acquired pneumonia: a randomised trial. Am J Respir Crit Care Med 2006, 174:84-93.
14. Stolz D, Christ-Crain M, Bingisser R, Leuppi J, Miedinger D, Müller C, Huber P, Müller B, Tamm M: Antibiotic treatment of exacerbations of COPD: a randomised, controlled trial comparing procalcitonin-guidance with standard therapy. Chest 2007, 131:9-19.

15. Hausfater P, Garric S, Ben Ayed, S. Rosenheim M, Bernard M Riou B: Usefulness of Procalcitonin as a marker of systemic infection in emergency department patients. Clin Infect Dis 2002, 34:895-901.

16. Hausfater P, Juillien G, Madonna-Py B, Haroche J, Bernard M, Riou B: Serum procalcitonin measurement as diagnostic and prognostic marker in febrile adult patients presenting to the emergency department. Crit Care 2007, 11:R60.

17. Rau BM, Kemppainen EA, Gumbs AA, Büchler MW, Wegscheider K, Bassi C, Puolakkainen PA, Beger HG: Early assessment of pancreatic infections and overall prognosis in severe acute pancreatitis by Procalcitonin (PCT). Ann Surg 2007, 245:745754.

18. Jebali M, Hausfater $\mathrm{P}$, Abbes $\mathrm{Z}$, Aouni Z, Riou B, Ferjani M: Assessment of the accuracy of procalcitonin to diagnose postoperative infection after cardiac surgery. Anesthesiology 2007, 107:232-238

19. Müller $B$, Schuetz $P$, Trampuz A: Circulating biomarkers as surrogates for bloodstream infections. Int $J$ Antimicrobial Agents 2007, 30S:S16-S23.

20. Nobre V, Harbarth S, Graf J-D, Rohner P, Pugin J: Use of procalcitonin to shorten antibiotic treatment duration in septic patients: a randomized trial. Am J Respir Crit Care Med 2008, 177:498-505.

21. Simon L, Gauvin F, Amre DK, Saint-Louis P, Lacroix J: Serum procalcitonin and $\mathrm{C}$-reactive protein levels as markers of bacterial infection: a systematic review and meta-analysis. Clin Infect Dis 2004, 39:206-217.

22. Uzzan B, Cohen R, Nicholas P, Cucherat M, Perret GY: Procalcitonin as a diagnostic test for sepsis in critically ill adults and after surgery or trauma: a systematic review and meta-analysis. Crit Care Med 2006, 34:1996-2003.

23. Jones AE, Fiechtl JF, Brown MD, Ballew J, Kline JA: Procalcitonin test in the diagnosis of bacteremia: a meta-analysis. Ann Emerg Med 2007, 50:34-41.

24. Tang BM, Eslick GD, Craig JC, McLean AS: Accuracy of procalcitonin for sepsis diagnosis in critically ill patients: systematic review and meta-analysis. Lancet Infect Dis 2007, 7:210-217.

25. Marc E, Ménager C, Moulin F, Stos B, Chalumeau M, Guérin S, Lebon P, Brunet F, Raymond J, Gendrel D: Procalcitonine et méningites virales: réduction des traitements antibiotiques inutiles par le dosage en routine au cours d'une épidémie [Procalcitonin and viral meningitis: reduction of unnecessary antibiotics by measurement during an outbreak]. Archives de Pediatrie 2002, 9:358-364 [in French].

26. ClinicalTrials.gov homepage [http://www.clinicaltrials.gov]

27. Current Controlled Trials homepage [http://www.controlled-trials.com].

28. Meisner M: Pathobiochemistry and clinical use of procalcitonin. Clin Chim Acta 2002, 323:17-29.

29. Tang BMP, McLean AS, Dawes IW, Huang SJ, Lin RCY: The use of gene-expression profiling to identify candidate genes in human sepsis. Am J Respir Crit Care Med 2007, 176:676-684.

30. Geppert A: Determination of troponin in the intensive care patient: please avoid "troponinitis". Crit Care Med 2005, 33: 1439-1441.

31. Amman P, Fehr T, Minder El, Günter C, Bertel O: Elevation of troponin $\mathrm{I}$ in sepsis and septic shock. Intens Care Med 2001, 27:965-969. 